\title{
HOMO CREATIVUM - MIT KREATYWNOŚCI W AGENCJACH REKLAMOWYCH
}

\author{
Abstract \\ HOMO CREATIVUM - THE MYTH OF CREATIVITY IN ADVERTISING \\ AGENCIES
}

During the economization of culture and the culturisation of the economy, creativity in the advertising industry has become a myth. The subject of this dissertation is a "discoursive oversweetening" resulting from the desire to raise the prestige of the so-called creative sector. The dissertation confronts mythical stories with the opinions presented by employees of Polish advertising agencies in accordance with the paradigm of radical humanism. The empirical part of the dissertation includes fourteen individual in-depth interviews with selected employees of the advertising industry. The collected research material allows to reveal problems, blockades and shortcomings in the aspect of behavior and pro-creative and pro-innovative attitudes. By immersing research in the perspective of Critical Management Studies, a holistic analysis of the phenomenon of creativity in the advertising industry will be carried out.

Key words: creativity, advertising agency, discoursive oversweetening, myth of creativity, humanities management

\section{Wstęp}

Jean-Jacques Hublin z niemieckiego Instytutu Maxa Plancka opublikował w 2017 roku wyniki badań dowodzące, że człowiek współczesny narodził się 100 tysięcy lat wcześniej, niż sądzono. Według niego gatunek człowieka współczesnego - homo sapiens - najbardziej doskonały w swej formie, liczy przeszło 300 tysięcy lat. Badania te rozpoczęły dyskusję nad umiejętnościami i zdolnościami człowieka rozumnego, 
które mogły rozwijać się znacznie dłużej, niż dotychczas myślanoํㅜㄹ co przekłada się na tempo rozwoju między innymi umiejętności miękkich oraz poszukiwań ich rudymentów w celu diagnozy stanu obecnego i możliwości dalszych „udoskonaleń”. Jedną z takich zdolności miękkich stanowi kreatywność, której oznaki posiadania wykazywały już najwcześniejsze gatunki z rodziny człowiekowatych i której źródła od lat poszukują psychologowie i socjologowie. W czasach prehistorycznych kreatywność zapewniała przeżycie, obecnie - choć nie w tak znacznym stopniu nadal decyduje ona o wielu aspektach naszego funkcjonowania. Zarówno kiedyś, jak i dziś kreatywność to pewien rodzaj przymusu. Kiedyś motywacją było przeżycie, dziś rynek pracy wymaga bycia kreatywnym w każdym miejscu, o każdej porze i w każdym zawodzie. Im większy jednak nacisk na kreatywność, tym więcej jej błędnych definicji, nieumiejętnego zarządzania działaniami twórczymi i decyzji menedżerów, które budują sferę mitów wokół człowieka kreatywnego - homo creativum. Oddziaływanie wspomnianych mitów stawia pracownika w dychotomii pomiędzy oczekiwaniami menedżerów i swoimi pragnieniami kreatywnej pracy a schematycznością wykonywanych zadań.

Badania przedstawione w niniejszym artykule stanowią efekt trzyletniej pracy autorki w różnych strukturach agencji reklamowych, zarówno na stanowiskach wykonawczych, jak i zarządczych. Agencje reklamowe zalicza się do tzw. sektora kreatywnego, którego precyzyjne zdefiniowanie nie jest łatwe ze względu na problemy w identyfikacji tego sektora, a samą działalność kreatywną trudno poddać sztywnym kryteriom klasyfikacji².

Praca oparta jest na założeniach paradygmatu radykalnego humanizmu, którego przyjęcie warunkowane jest subiektywnym podejściem do badanej rzeczywistości społecznej oraz chęcią dokonania radykalnej zmiany w badanym obszarze. Jednocześnie badaczka poddaje analizie powszechnie przyjęte twierdzenia tworzące mity denaturalizacji oraz przyjmuje antyperformatywną i refleksyjną postawę zgodnie z założeniami nurtu krytycznego w zarządzaniu (critical management studies) $)^{3}$, odpowiadającego paradygmatowi radykalnego strukturalizmu. Tym samym łamie zasadę wierności tylko jednemu paradygmatowi promowaną przez Gibsona Burrella i Garetha Morgana ${ }^{4}$. Badania ze względu na dokonaną triangulację paradygmatyczną oraz metodologiczną stanowią holistyczne opracowanie badanego problemu.

1 J.-J. Hublin, New Fossils from Jebel Irhoud, Morocco and the Pan-African Origin of Homo Sapiens, „Nature” 2017, t. 546, s. 289-292.

${ }^{2}$ K. Stachowiak, Problemy metodologiczne badania sektora kreatywnego, [w:] P. Churski (red.), Rozwój regionalny i polityka regionalna, Bogucki Wydawnictwo Naukowe, Poznań 2015, s. 9-13.

${ }^{3}$ M. Zawadzki, Rola i miejsce nurtu krytycznego w naukach o zarządzaniu, „Culture Management" 2012, nr 5 (5).

${ }^{4}$ G. Burrell, G. Morgan, Sociological Paradigms and Organizational Analysis, Heinemann, London 1979. 
W ramach badań przeprowadzonych zostało 14 indywidualnych wywiadów swobodnych pogłębionych z pracownikami polskich agencji reklamowych o różnym profilu: agencje 360 stopni, agencje interaktywne, agencje marketingowe, agencje eventowe. W niniejszym artykule poszczególne wypowiedzi zostały oznaczone sfalsyfikowanymi imionami ze względu na konieczność anonimizacji osób badanych zgodnie z ich wolą. Metodami wspierającymi prowadzone badania były: autoetnografia organizacji oraz analiza źródeł pisanych. Wybór metod jakościowych dyktowany jest humanistyczną refleksją, która w centrum badania stawia człowieka jako twórcę organizacji.

\section{Kreatywność w erze ekonomizacji kultury i kulturalizacji gospodarki}

Proces ekonomizacji kultury i kulturalizacji gospodarki nieustannie trwa, skutkiem czego kreatywność jako twór kulturowy staje się towarem ${ }^{5}$. Wizja rynkowa kultury zakłada gospodarcze wykorzystanie kultury i jej wytworów ${ }^{6}$. Analiza kreatywności z perspektywy ekonomicznej wysuwa na pierwszy plan zyski i straty implikowane próbami implementacji działań twórczych w wielu branżach. Tymczasem kreatywność to cecha, właściwość, atrybut istoty ludzkiej, która z jednej strony jest źródłem, z drugiej zaś stanowi punkt odniesienia podejmowanych działań zgodnie z teorią antropocentryczną przedstawianą przez Barbarę Czarniawską ${ }^{7}$ - teoretyczkę i praktyczkę nurtu zarządzania humanistycznego.

Rozumienie pojęcia kreatywności zmienia się wraz z przyjmowaną przez badaczy perspektywą. Zgodnie z koncepcją ekonomiczną nacisk kładziony zostaje na efekt kreatywności, czyli produkty lub usługi kreatywne przekładające się na wzrost gospodarczy. Takie podejście przyjmuje między innymi twórca koncepcji 3T (Talent, Technologia, Tolerancja) - Richard Florida ${ }^{8}$, czy grupa badaczy: Richard W. Woodman, John E. Sawyer oraz Ricky W. Griffin', dla których kreatywność to efekt współpracy jednostek tworzących użyteczne i wartościowe produkty, usługi, pomysły czy idee. Środowisko związane z perspektywą humanistyczną zwraca uwagę na sam akt twórczy, który dokonuje się dzięki wysiłkowi ludzkiego umysłu, lub też misję, która w odróżnieniu od koncepcji ekonomicznych składa się na pomoc człowiekowi lub grupie ludzi, nie wzrost aktywów finansowych. Julia Cameron

${ }^{5}$ UNCTAD, Creative Economy. Report [dok. elektr.], http://www.unctad.org/en/docs/ditc20082cer_en.pdf (dostęp: 18.12.2018).

${ }^{6}$ K. Kopecka-Piech, Spory o przemysty kreatywne, „Kultura i Edukacja” 2013, nr 3 (96), s. 64.

7 B. Czarniawska, Zarządzanie humanistyczne czy zarządzanie ludzkie?, [w:] B. Nierenberg, R. Batko, Ł. Sułkowski (red.), Zarządzanie humanistyczne, Wydawnictwo Uniwersytetu Jagiellońskiego, Kraków 2015, s. 16.

${ }^{8}$ R. Florida, Narodziny klasy kreatywnej, Narodowe Centrum Kultury, Warszawa 2010, s. 9.

9 R.W. Woodman, J.E. Sawyer, R.W. Griffin, Toward a Theory of Organizational Creativity, „Academy of Management Review" 1993, nr 18 (2), s. 293-321. 
- amerykańska poetka i dziennikarka - stawia za cel kreatywności osiągnięcie warstwy duchowej ${ }^{10}$, Morris I. Stein podkreśla fakt, iż produkt powstały w procesie kreatywności powinien pełnić przede wszystkim funkcję użyteczną dla danej społeczności w danym czasie ${ }^{11}$. Innymi słowy, powinien być przydatny i pożyteczny. Takie rozumienie kreatywności sprowadza jej nadrzędną funkcję do identyfikacji problemów, które istnieją $\mathrm{w}$ danej społeczności, oraz tworzenia przy wykorzystaniu własnych zdolności takich rozwiązań, które uzyskują społeczne uznanie ${ }^{12}$. Niejednokrotnie, zgodnie z definicją amerykańskiej socjolożki Rosabeth Moss Kanter, badającej wpływ systemów biurokratycznych na innowacje w organizacji, tworzenie produktów kreatywnych wymaga dekonstrukcji schematu posiadanych informacji i możliwości układania oraz segregowania ich na nowo ${ }^{13}$.

Kreatywność implikuje bowiem otwartość na zmiany, które są konieczne w procesie innowacyjności. Ważnym aspektem staje się tolerancja będąca podstawowym warunkiem przy tworzeniu produktu kreatywnego. Koncepcję tę podkreśla brytyjski badacz (mający swoje korzenie w naukach biologicznych, obecnie zajmujący się procesami przetwarzania danych) Robert B. Mellor, wymieniając trzy podstawowe źródła kreatywności i stawiając akceptację odmienności na pierwszym miejscu. Zgodnie z jego założeniami wpływ na innowacyjność ma odmienność, kreatywność oraz wynalazczośćc ${ }^{14}$. W organizacji wyzwaniem dla kadry zarządzającej jest zapewnienie takich warunków, aby wymienione źródła kreatywności mogły zaistnieć. Kluczowym działaniem menedżerów powinno być dążenie do minimalizowania barier kreatywności oraz maksymalizowania szans do jej zaistnienia. Tymczasem w środowisku agencji reklamowych nadal panuje wymóg procesów kreatywnych bez wsparcia kierownictwa wyższych rzędów w każdej z warstw składających się na organizację zgodnie z perspektywą teorii organizacji Mary Jo Hatch ${ }^{15}$.

Gloryfikacja kreatywności następuje na wszystkich polach badawczych, jednak w perspektywie ekonomicznej brakuje refleksji nad konsekwencjami wymogu kreatywności, która staje się opresją organizacji wobec pracownika. Ekonomizacja kultury oraz kulturalizacja gospodarki często przybierają fałszywe szaty, których efektem jest dyskursywne przesłodzenie. Mity upraszczają rzeczywistość, tworząc tym samym fasadę kulturalizacji tego, co w rzeczywistości poddane jest jedynie mechanizmom rynkowym. Stąd tak głębokie zainteresowanie kreatywnością w kontekście ekonomicznych systemów. Warto chociażby przytoczyć w tym miejscu badania Richarda Floridy, który gloryfikuje kreatywność, wyróżniając klasy kreatywne,

10 J. Cameron, The Artist's Way: A Spiritual Path to Higher Creativity, Pan Books, London 1995.

${ }_{11}$ M.I. Stein, Creativity and Culture, „Journal of Psychology” 1953, t. 36.

12 R.K. Sawyer, Explaining Creativity - The Science of Human Innovation, Oxford University Press, Oxford 2006, s. 27.

${ }_{13}$ R.M. Kanter, eVolve!: Succeeding in the Digital Culture of Tomorrow, Harvard Business School Press, Boston 2001, s. 261.

${ }^{14}$ R.B. Mellor, Kreatywność, [w:] R.B. Mellor, G. Coulton, A. Chick, A. Bifulco, N. Mellor, A. Fisher (red.), Przedsiębiorczość, PWE, Warszawa 2011, s. 48.

${ }^{15}$ M.J. Hatch, Teoria organizacji, Wydawnictwo Naukowe PWN, Warszawa 2002. 
obszary o większym poziomie kreatywności oraz superkreatywnych pracowników ${ }^{16}$. Innymi słowy, tworzy i wyodrębnia elitarne środowisko, do którego wstęp mają tylko nieliczni. Warunkiem przynależności jest uzyskanie odpowiedniego poziomu kreatywności według wskaźników wymienianych przez Floridę: wskaźnik wysokich technologii, innowacyjności, gejów, bohemy, talentu, tygla oraz różnorodności.

Żyjemy w czasach wielkich nadziei. Stworzyliśmy systemy społeczno-ekonomiczne, które wykorzystują ludzką kreatywność w stopniu dotąd niespotykanym. To z kolei stanowi wyjątkową okazję do podniesienia stopy życiowej, zbudowania bardziej ludzkiej, zrównoważonej gospodarki oraz do tego, by nasze życie stało się pełniejsze ${ }^{17}$.

Gloryfikacja kreatywności przez Floridę oraz dopatrywanie się w niej potencjału gospodarczego prowadzącego do poprawy poziomu życia ludności i osiągnięcia stanu zrównoważonej gospodarki, a także ilość i jakość badań nad tym obszarem wskazują na fakt, że mamy do czynienia z modą na kreatywność, niejednokrotnie niepodpartą realnymi działaniami zmierzającymi w stronę maksymalizacji działań kreatywnych. Sytuacja, w której kreatywność staje się przymusem pracowników, przesłania inne wartości w organizacji i często zaczyna przeradzać się w formę opresji, wymaga refleksji i interwencji. Stan ten przybiera postać analogiczną do tej, która zaistniała u początków perspektywy krytycznej. Nurt krytyczny w zarządzaniu stworzony przez Matsa Alvessona i Hugh Willmotta jest bowiem zakorzeniony w walce $\mathrm{z}$ nadmiernym kultem menedżera i menedżeryzmu, który stanowi niejednokrotnie przekłamaną wizję zarządzania ${ }^{18}$. Tym samym korzystając z dorobku oraz metod wypracowanych przez środowisko krytyczne, należy poddać procesowi denaturalizacji powszechnie funkcjonujące przekonania utrwalające nieprawdziwą wizję organizacji i wzmacniające efekt odziaływania postprawdy ${ }^{19}$.

Stojąc na rozdrożu między artystyczną i ekonomiczną wizją kultury ${ }^{20}$ oraz zamkniętą w ich obrębie kreatywnością, trzeba szukać, podążając tropem Jana Szomburga, połączeń „(...) między tymi dwiema sferami: artystycznej kreacji i ekonomicznej produkcji - traktowanymi dotychczas zupełnie odrębnie - (...) należy zbudować nowe mosty, nowe, wzajemnie korzystne powiązania”21.

${ }^{16}$ R. Florida, Narodziny klasy kreatywnej, dz. cyt.

17 Cyt. za: tamże, s. 9.

${ }^{18}$ M. Zawadzki, Rola i miejsce nurtu krytycznego..., dz. cyt.

19 R. Keyes, Czas postprawdy. Nieszczerość i oszustwa w codziennym życiu, Wydawnictwo Naukowe PWN, Warszawa 2017.

${ }^{20}$ K. Stachowiak, Problemy metodologiczne badania..., dz. cyt., s. 14-16.

${ }^{21}$ J. Szomburg, Kultura i przemysty kultury szansą rozwojowa dla Polski, [w:] J. Szomburg (red.), Kultura i przemysly kultury szansą rozwojową dla Polski, Instytut Badań nad Gospodarką Rynkową, Gdańsk 2002, s. 10. 


\section{W świecie mitów}

Mity zwykły kojarzyć się z ułudą, bajkowymi lub baśniowymi opowieściami, wymyślonymi historiami. Funkcją mitu nie jest jednak niesienie prawdy, lecz objaśnianie rzeczywistości poprzez jej upraszczanie. Pierwszych mitów możemy doszukiwać się już w twórczości człowieka rozumnego - homo neanderthalensis, który za pomocą opowieści zachowywał pamięć o bliskich zmarłych ${ }^{22}$.

W świecie organizacji mity pełnią niejednokrotnie funkcję wyobrażeniową. Brytyjska publicystka Karen Armstrong, światowej klasy autorytet w dziedzinie religioznawstwa, podkreśla znaczenie mitów w tworzeniu alternatywnej rzeczywistości w stosunku do tej, którą doświadczamy na co dzień. Armstrong nazywa ją „światem dóbr", czyli sferą utopii, do której chcemy dążyć, ale której z różnych powodów nie jesteśmy w stanie osiągnąćc ${ }^{23}$.

Wyobrażenie o takim świecie tworzone jest przez superkreatywne agencje reklamowe, które snują wizje o superkreatywnych pracownikach wykonujących bezustannie superkreatywne czynności. Jak się jednak okazuje na podstawie badań, to mit, który powielany jest w branży reklamowej zarówno przez menedżerów, jak i pracowników. Celem i jednych, i drugich jest ucieczka przed rzeczywistością, która nie wygląda tak atrakcyjnie jak w mitycznych opowieściach.

Rose: Pracownik, który wstaje rano i z radością biegnie do pracy, by móc wykorzystywać swoje pokłady kreatywności - jest to mit. Na tyle różnych pracy, jakie wykonywałam w branży reklamowej, nigdy nie spotkałam się z taką osobą.

Świadomość powielania oraz przedłużania mitycznych opowieści jest wypierana ze względu na bezpieczeństwo w ocenie swoich predyspozycji, wartości i poprawy wizerunku. Tworzy się w ten sposób sens wyobrażeniowy wspólnoty, która odtwarza schematy myślowe, odwołując się do utartych i powszechnie przyjętych artefaktów, norm, znaczeń i symboli ${ }^{24}$. W konsekwencji dochodzi do zaburzenia tożsamości jednostek w organizacji oraz pewnego rodzaju przemocy symbolicznej opisywanej przez przedstawicieli postmodernizmu w zarządzaniu (Barbara Czarniawska, Mary Jo Hatch, Gibson Burrell) ${ }^{25}$. Kreatywność oparta na otwartości, egalitaryzmie i wolnym wyborze staje się przymusem, wartością narzuconą, która przeradza się w presję bycia kreatywnym. Składa się to na kształtowanie nietransparentnej kultury organizacyjnej wpływającej na podziały, których kryterium stanowi poziom immersji w sferę wytworzonych mitów.

22 J. Habermas, Knowledge and Human Interests, Beacon Press, Boston 1972.

${ }^{23}$ K. Armstrong, A Short History of Myth, vol. 1, Canongate Books, Edinburgh-London-New York-Melbourne 2004, s. 1-3.

${ }^{24}$ C. Lévi-Strauss, Struktura mitu, [w:] K. Pomian, Antropologia strukturalna, Państwowy Instytut Wydawniczy, Warszawa 1970, s. 77.

${ }^{25}$ Ł. Sułkowski, Czy warto zajmować się kultura organizacyjna, „Zarządzanie Zasobami Ludzkimi” 2008, nr 6, s. 9-25. 


\section{Kultura organizacyjna kluczem do kreatywności}

Mary Jo Hatch wyróżniała cztery główne obszary składające się na organizację, podkreślając mnogość wpływów (impulsów) dostarczanych przez inspiracje akademickie i pozaakademickie ${ }^{26}$. Zakresów tych nie sposób od siebie odseparować, co skutkuje wzajemnym oddziaływaniem na siebie struktur. Jednocześnie nacisk położony na jeden $\mathrm{z}$ aspektów wielokrotnie powoduje zaburzenia pozostałych.

\section{Struktura fizyczna}

Pierwsze badania struktury fizycznej odbyły się na przełomie lat 20. i 30. XX wie$\mathrm{ku}$ w fabryce Hawthorne Works ${ }^{27}$. Od tamtej pory zainteresowanie wyglądem oraz umiejscowieniem organizacji nieustannie wzrasta. Według Hatch na strukturę fizyczną składają się trzy główne elementy: geografia (lokalizacja, w której znajduje się organizacja), rozkład przestrzenny (rozłożenie budynków) oraz architektura i wystrój (przyjęty przez organizację styl) ${ }^{28}$.

\section{Struktura technologiczna}

Rozumiana jako infrastruktura technologiczna pozwalająca na transakcje czynników wejściowych (input) w czynniki wyjściowe (output) ${ }^{29}$. W kontekście branży reklamowej kluczowym pojęciem staje się technologia wysoko zaawansowana, cechująca się stochastycznością, ciągłością oraz abstrakcyjnością ${ }^{30}$.

\section{Struktura społeczna}

Hatch dostrzega zmianę klasycznych struktur społecznych opartych na hierarchiczności oraz sztywnych relacjach i regułach na struktury sieciowe oraz wirtualne, skupione na elastyczności, współpracy i współdzieleniu ${ }^{31}$.

${ }^{26}$ M.J. Hatch, Teoria organizacji, dz. cyt.

${ }^{27}$ W. Piotrowski, Organizacja i zarządzanie - kierunki, koncepcje, punkty widzenia, [w:] A. Koźmiński, W. Piotrowski, Zarządzanie - teoria i praktyka, Wydawnictwo Naukowe PWN, Warszawa 1996, s. 602-605.

${ }^{28}$ M.J. Hatch, Teoria organizacji, dz. cyt., s. 244.

29 Tamże, s. 137-139.

${ }^{30} \mathrm{~K}$. Weick, Tworzenie sensu $w$ organizacjach, Wydawnictwo Uniwersytetu Jagiellońskiego, Kraków 2016.

${ }^{31}$ M.J. Hatch, Teoria organizacji, dz. cyt., s. 167. 


\section{Struktura kulturowa}

Hatch stawia kulturę organizacyjną w pozycji wypadkowej wpływu otoczenia wewnętrznego oraz zewnętrznego na organizację. Jednocześnie badaczka kładzie największy nacisk na otoczenie wewnętrze, podkreślając znaczenie osób tworzących organizację $e^{32}$.

Z badań (wywiadów swobodnych pogłębionych z pracownikami agencji i firm kreatywnych) przeprowadzonych na potrzeby niniejszej pracy wynika, że kluczową rolę $\mathrm{w}$ aspekcie kreatywności w branży reklamowej odgrywa kultura organizacyjna, która rozumiana jest odmiennie w zależności od wyboru przez badaczy w nurcie zarządzania humanistycznego odpowiedniego paradygmatu. Pozostałe elementy teorii organizacji, takie jak technologia, struktura społeczna czy fizyczna, nie pozostają jednak bez znaczenia. W kontrze do przedstawicieli paradygmatów radykalnego strukturalizmu, funkcjonalizmu czy interpretatywizmu, a zgodnie z socjologicznym podziałem Burrella i Morgana, postmoderniści przyjmują antysystemowe podejście odrzucające konieczność określenia kultury organizacyjnej jako konkretnego bytu (tworu). Tym samym podkreślają swobodę kształtowania kultury, której nie można zamknąć w sztywne ramy struktury w organizacji ${ }^{33}$. Jednocześnie jest to pomost łączący kulturę organizacyjną i kreatywność, która poniekąd $\mathrm{z}$ niej wynika. Koncepcja ta jest zbieżna z perspektywą Zbigniewa Baumana, według którego kultura „uczy nowego spojrzenia, uczy względności każdego spojrzenia, demaskuje konwencje (...), burzy spokój ducha i wzbudza niepewność siebie, odstręcza od dogmatyzmu i nietolerancji” ${ }^{34}$. Innymi słowy, realizuje cele, które leżą u podstaw kreatogennych zachowań.

Tabela 1. Wpływ wybranych elementów kultury organizacyjnej na poziom kreatywności w agencjach reklamowych

\begin{tabular}{|l|l|l|l|}
\hline $\begin{array}{c}\text { Element kultury orga- } \\
\text { nizacyjnej }\end{array}$ & \multicolumn{1}{|c|}{$\begin{array}{c}\text { Wyszczególnienie - } \\
\text { przykłady }\end{array}$} & $\begin{array}{c}\text { Wpływ na poziom } \\
\text { kreatywności }\end{array}$ & $\begin{array}{c}\text { Liczba osób potwier- } \\
\text { dzająca wpływ elemen- } \\
\text { tu na kreatywność (na } \\
\text { 14 badanych w wywia- } \\
\text { dach pogłębionych) }\end{array}$ \\
\hline misja, wizja, big idea & $\begin{array}{l}\text { „Najdroższą walutą są } \\
\text { dla nas dobre pomysły }\end{array}$ & średni & 6 osób \\
\hline styl/sposób kierowania & $\begin{array}{l}\text { demokratyczny, libe- } \\
\text { ralny }\end{array}$ & duży & 9 osób \\
\hline
\end{tabular}

32 Tamże, s. 204-205.

${ }^{33}$ Ł. Sułkowski, Czy warto zajmować się kultura organizacyjna, dz. cyt., s. 9-25.

${ }^{34}$ Cyt. za: Z. Bauman, A. Zeidler-Janiszewska, R. Kubicki, Wobec sztuki, [w:] tychże, Humanista w ponowoczesnym świecie, Wydawnictwo Zysk i S-ka, Poznań, 1997, s. 102-104. 


\begin{tabular}{|c|c|c|c|}
\hline rytuały & $\begin{array}{l}\text { wspólne śniadania, } \\
\text { wyjście na przerwę } \\
\text { o określonej godzinie }\end{array}$ & bardzo duży & 13 osób \\
\hline język, slang & $\begin{array}{l}\text { deadline, feature, } \\
\text { adwordsy }\end{array}$ & duży & 9 osób \\
\hline ubiór & nieformalny, formalny & bardzo duży & 13 osób \\
\hline atmosfera w pracy & $\begin{array}{l}\text { luźna, sztywna, ro- } \\
\text { dzinna }\end{array}$ & duży & 11 osób \\
\hline \multicolumn{4}{|c|}{$\begin{array}{l}\text { Legenda: } \\
\text { 1-4 osób: mały } \\
\text { 5-8 osób: średni } \\
\text { 9-12 osób: duży } \\
\text { 13-14 osób: bardzo duży }\end{array}$} \\
\hline
\end{tabular}

Źródło: opracowanie na podstawie badań własnych.

Powyższa tabela obrazuje wpływ wybranych czynników kultury organizacyjnej na poziom kreatywności. Jak wynika $\mathrm{z}$ badań, największe znaczenie $\mathrm{w}$ analizowanym obszarze mają rytuały dnia codziennego, takie jak: wspólne picie kawy, rozmowy, posiłki o wyznaczonej porze dnia oraz ubiór przybierający w większości organizacji branży reklamowej postać nieformalną. Elementy te stanowią najniższy poziom kultury organizacyjnej, który jest dostrzegalny przez wszystkich członków firmy w różnym stopniu. Refleksja nad znaczeniem kultury organizacyjnej w stosunku do kreatywności pozwala dostrzec fundamentalne postawy, wzory i zachowania, które są wielokrotnie pomijane przez menedżerów skupionych na zarządzaniu strategicznym z pominięciem kultury.

Lucy: Swoboda przede wszystkim, tak by czuć się dobrze. Myślę, że zamknąć się w schemat garnituru w takim miejscu - w agencji reklamowej - to nie jest dobry pomysł. Nie można być kreatywnym w ściśle zapiętym po ostatni guzik garniturze. (...) Dobrze, że czujemy się swobodnie i to nam daje swobodę myślenia.

Pracownicy agencji reklamowych, zgodnie z koncepcją psychologa Edgara Scheina, łączą elementy kultury organizacyjnej z całokształtem procesów myślowych. Odbywa się to na wszystkich trzech poziomach: 1) założeń, 2) wartości i norm, 3) artefaktów i symboli ${ }^{35}$. Sposób ubioru, będący dla nich swoistego rodzaju symbolem, przekłada się na wyznawane wartości i normy, a następnie na założenia - najmniej widoczne i wyraźne, tkwiące w podświadomości członków organizacji. W analogiczny sposób następuje proces kulturowy innych aspektów wpływających na poziom kreatywności.

Emily: Fotel, który jest w naszym logo, to jest fotel, który należał do pradziadka Alberta [jednego z założycieli firmy - przyp. K.G.]. Pradziadek siedział na nim i opowiadał wnukom bajki, a teraz ten fotel jest w naszej agencji. Czasami, kiedy sobie coś wymyślamy, siadamy na nim i jest to dla nas takie magiczne miejsce.

${ }^{35}$ E.H. Schein, Organizational Culture and Leadership, Jossey-Bass, San Francisco 1995, s. 14. 
Członkowie organizacji są nastawieni na działania proinnowacyjne i prokreatywne, dlatego symbole, takie jak fotel, długopis, maskotka czy inne symbole kreatywności (identyfikowane tylko przez daną społeczność), stanowią bodziec do procesu twórczego myślenia. Jednocześnie jest to wewnętrzny kod, który spaja organizację, wpływając na komunikację międzyludzką.

Kolejnymi aspektami, które zostały poddane badaniu, są blokady oraz motywatory do działań kreatywnych w agencjach reklamowych. Okazuje się, że pracownicy są w stanie wymienić wiele barier, wśród których najbardziej istotnymi są: czas, warunki pracy, decyzje/wytyczne klientów oraz budżet przeznaczony na proces kreatywny, a także jego estymację.

\section{Rysunek 1. Proces wzajemnego oddziaływania podstawowych barier kreatywności w branży reklamowej}
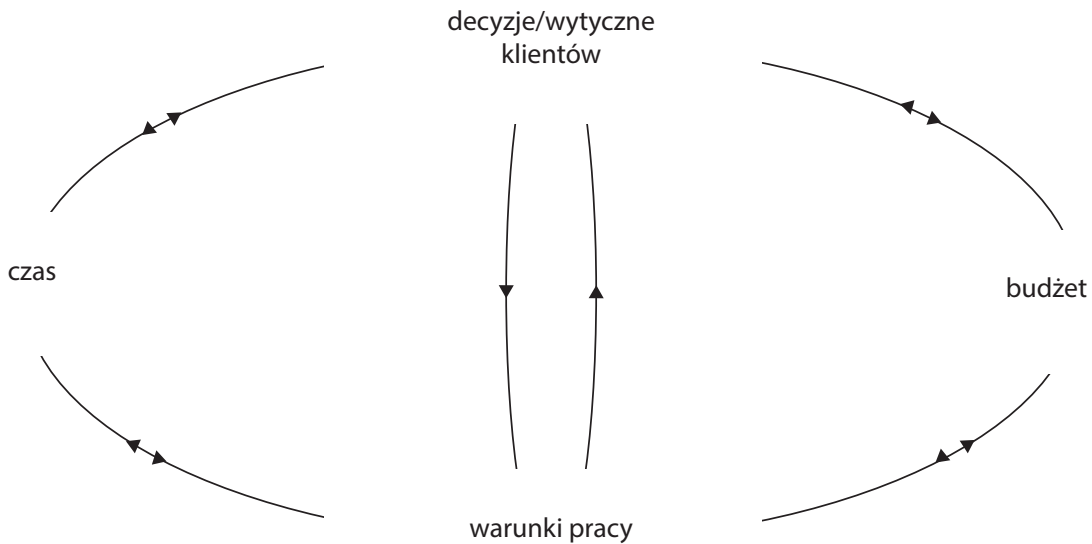

Źródło: opracowanie na podstawie badań własnych.

Na powyższym wykresie ujęty został wzajemny wpływ kluczowych w agencjach reklamowych barier kreatywności. Jak uważają badani, decyzje/wytyczne klientów są czynnikiem hamującym kreatywność poprzez schematyczne i często konserwatywne myślenie o kampaniach reklamowych. W rezultacie narzucane zostają wzorce wykorzystywane $\mathrm{w}$ innych reklamach lub te, które powstały kilkanaście lat temu. Implikuje to proces odtwórczy polegający na powieleniu mechanizmów, które funkcjonowały w przypadku innych kampanii, ograniczając tym samym innowacyjność autorów kampanii.

Czynnik ten wiąże się z czasem na wytworzenie produktu kreatywnego oraz budżetem przeznaczonym na jego wykonawstwo. Stres związany z presją czasu jest spowodowany zbyt wieloma projektami realizowanymi jednocześnie, funkcjonowaniem $\mathrm{w}$ systemie tzw. from deadline to deadline, niezapowiedzianym zwiększaniem zakresu prac i naciskiem ze strony klientów na jak najszybsze dostarczenie produktu. Jak podkreślają badani, zarówno czas, jak i budżet są dopasowywane do 
potrzeb klienta często bez uwzględnienia charakteru prac nad kampanią reklamową. W efekcie wielokrotnie powstaje niemożność pełnej realizacji kampanii oraz ograniczenie kreatywnych form kampanii na rzecz oszczędności czasu i finansów.

$\mathrm{Z}$ rozmów z pracownikami agencji reklamowych wynika, że sztywne ramy działania ustalane przez osoby spoza procesu kreatywnego, niedopasowany czas i budżet oraz warunki pracy (w tym kultura organizacyjna) ograniczają kreatywność. Potwierdzają to również badania Rafała Drozdowskiego i jego współpracowników przeprowadzone dla Polskiej Agencji Rozwoju Przedsiębiorczości, które dowodzą, że:

(...) barierą dla kreatywności i innowacyjności jest duża liczba stresorów towarzyszących pracy i związane z nią, permanentne poczucie zagrożenia. Kreatywność i innowacyjność wymagają dużego poczucia bezpieczeństwa. Nie musi i nawet nie powinno być ono utożsamiane $\mathrm{z}$ bezpieczeństwem socjalnym; chodzi raczej o bezpieczeństwo rozumiane jako prawo do odrębnego zdania, jako poczucie przewidywalności zachowań organizacji (wymagające z kolei jej stabilności proceduralnej) ${ }^{36}$.

$\mathrm{Z}$ jednej strony pracownicy agencji reklamowych zmagają się z blokadami kreatywności, z drugiej zaś z brakiem zachowań proinnowacyjnych w organizacjach. Jak zauważają, istnieje wiele metod wspierających innowacyjność projektową, między innymi zespołowe burze mózgów, które często jednak nie są wykorzystywane lub są świadomie pomijane przez menedżerów zespołów kreatywnych. Tymczasem proinnowacyjne metody pracy są nie tylko lubiane przez pracowników, ponieważ przełamują schematyczność pracy, lecz także umożliwiają osiąganie lepszych efektów i zwiększenie efektywności pracy.

Megan: Odkrywamy swoją kreatywność nawzajem. Czasami nawet nie wiemy, że ktoś ma jakiś dobry pomysł, ponieważ nie chce się wypowiedzieć na forum, a jak już robimy burzę mózgów, to oczekujemy, żeby każdy się wypowiedział w tej kwestii, i wtedy każda osoba zostanie usłyszana.

Emily: Po godzinie pracy indywidualnej siadamy razem, wymyślamy i zazwyczaj wtedy wychodzą najlepsze pomysły, kiedy każdy przynosi swoje inspiracje i łączymy to w całość.

Judith: Zawsze jak przychodzi brief kreatywny, to organizujemy burzę mózgów i, co ciekawe, w tych spotkaniach nie biorą udziału tylko osoby z działu kreatywnego, ale cała agencja - ktokolwiek nie jest wtedy w biurze: księgowa, event managerowie, technicy i tak dalej. (...) To jest ten pierwszy moment, kiedy staramy się wymyślić big idea i robimy to wszyscy, a potem już w mniejszych grupach prowadzimy zespołowe burze mózgów.

${ }^{36}$ R. Drozdowski, A. Zakrzewska, K. Puchalska, M. Morchat, D. Mroczkowska, Wspieranie postaw proinnowacyjnych przez wzmacnianie kreatywności jednostki, Polska Agencja Rozwoju Przedsiębiorczości, Warszawa 2010, s. 114. 
Proinnowacyjne metody pracy to narzędzia służące do pobudzenia kreatywności; innym ważnym czynnikiem w tym obszarze jest kultura organizacyjna.

Rysunek 2. Cechy kultury organizacyjnej sprzyjającej kreatywności i innowacyjności

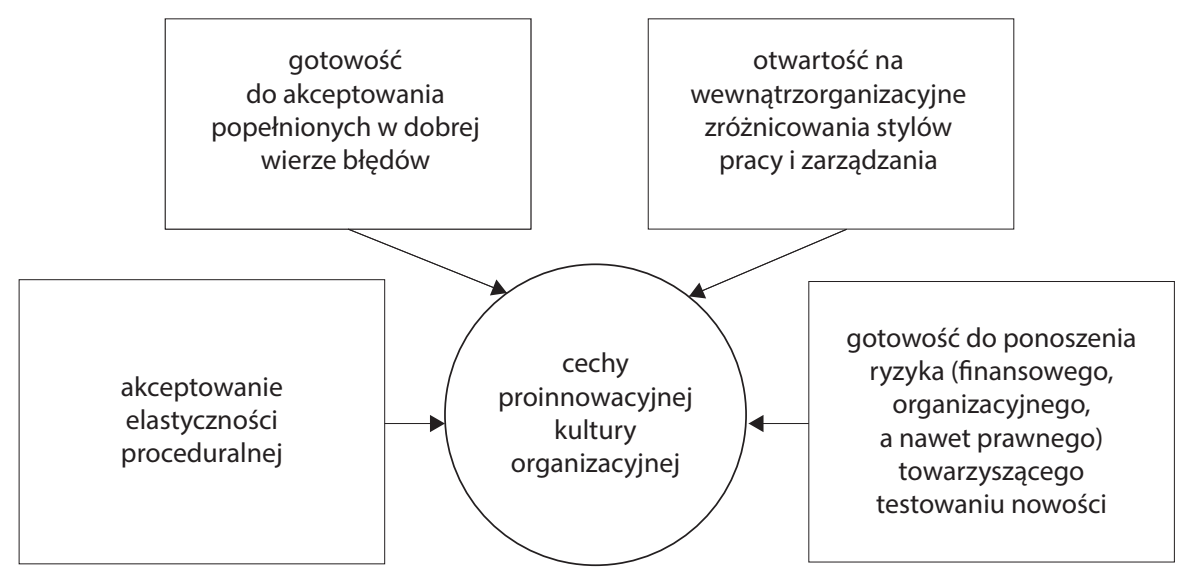

Źródło: R. Drozdowski i in., Wspieranie postaw proinnowacyjnych przez wzmacnianie kreatywności jednostki, Polska Agencja Rozwoju Przedsiębiorczości, Warszawa 2010, s. 113.

Jak podkreśla Rafał Drozdowski i inni badacze postaw proinnowacyjnych przez wzmacnianie kreatywności jednostki, wśród kluczowych cech kultury organizacyjnej w tym zakresie jest gotowość i przyzwolenie na popełnianie błędów sprzyjające procesowi weryfikowanego uczenia się oraz gotowość do ponoszenia ryzyka. Jednocześnie ważna jest otwartość na różnorodność, zwłaszcza w zakresie stylów pracy i zarządzania, oraz akceptowanie elastyczności proceduralnej pracowników.

Jak wynika z wywiadów przeprowadzonych z pracownikami agencji reklamowych, zadaniem menedżerów chcących tworzyć i realizować kreatywne projekty jest stworzenie warunków bez blokad/barier kreatywności oraz dbałość o kulturę organizacyjną wspierającą proinnowacyjne postawy i narzędzia.

\section{Zakończenie}

Gdzie zaczyna się i kończy kreatywnossć? Jak zbadać jej granice i zmierzyć wartość? Ile w kreatywnym pracowniku kreatywności, a ile mitycznego wyobrażenia? Czy da się zamknąć kreatywność w drewnianej skrzyni i chronić niczym skarb? Wreszcie - czy warto? Choć ilość badań w zakresie kreatywności, prokreatywnych i proinnowacyjnych postaw oraz społeczeństw kreatogennych wzrasta z roku na rok, nie uzyskano jednoznacznej odpowiedzi na powyższe pytania. Florida mitologizuje kreatywność i próbuje ją mierzyć, jednak jego wyniki trudno uznać za wymierne. 
Inni badacze, naśladując Floridę (m.in. Krzysztof Klincewicz ${ }^{37}$ ), powielają stworzony przez niego mit. Istota ludzka zostaje zamknięta w sztywnych ramach opartych na wskaźnikach, które decydują o przynależności do elitarnej społeczności klasy kreatywnej.

Na kanwie mitów i opowieści, które pozornie upraszczają rzeczywistość, powstaje kreatywny pracownik agencji reklamowej - demiurg pełen nieszablonowych pomysłów, skłonny do inspiracji i innowacyjnych rozwiązań. Tymczasem to tylko fasada. Za nią kryje się istota ludzka wtłoczona w sztywne ramy bycia kreatywnym. Organizacja staje się opresantem, który stawia pracowników agencji reklamowej w dychotomii między postawą prokreatywną a chęcią uwolnienia się od niej. Kreatywność - wartość oparta na swobodzie twórczej - przybiera postać mentalnego więzienia.

Założenia nurtu krytycznego, w szczególności refleksja humanistyczna, pozwalają na podanie w wątpliwość zasadności funkcjonowania i rozwoju mitów na temat kreatywności w branży reklamowej oraz ich skutków.

Prawdziwym wyzwaniem naszych czasów jest dokończenie budowy systemu, który zaczął się już tworzyć, czyli zbudowanie społeczeństwa kreatywnego, które umiałoby wykorzystać wyzwoloną przez nas energię twórczą oraz złagodzić spowodowane przez nią zawirowania i zamęt ${ }^{38}$.

Powyższe stwierdzenie Floridy napawa lękiem i skłania do radykalnej zmiany. Prawdziwym wyzwaniem naszych czasów, zgodnie z perspektywą humanistyczną, jest bowiem wyrwanie kreatywności ze sztucznego systemu i doprowadzenie do stanu, w którym każda istota ludzka będzie sama decydować o swojej kreatywności, a zadaniem menedżerów będzie wspieranie proinnowacyjnych postaw i eliminowanie blokad kreatywności.

W czasach ekonomizacji kultury i kulturalizacji ekonomii pytanie o człowieka stanowi nadrzędny cel. Im szybciej menedżerowie branży reklamowej uświadomią sobie znaczenie kultury organizacyjnej kształtowanej przez ludzi i odrzucą jednokierunkowe pojmowanie kreatywności przez pryzmat jedynie ekonomicznych aspektów, tym większa szansa na realną kreatywność pracowników.

\section{Bibliografia}

Armstrong K., A Short History of Myth, vol. 1, Canongate Books, Edinburgh-London-New York-Melbourne 2004.

${ }^{37}$ K. Klincewicz, Koncepcja klasy kreatywnej Richarda Floridy i klasa kreatywna w Polsce, [w:] K. Klincewicz (red.), Klasa kreatywna w Polsce - technologia, talent i tolerancja jako źródła rozwoju regionalnego, Wydawnictwo Naukowe Wydziału Zarządzania Uniwersytetu Warszawskiego, Warszawa 2012.

${ }^{38}$ Cyt. za: R. Florida, Narodziny klasy kreatywnej, dz. cyt., s. 10. 
Bauman Z., Zeidler-Janiszewska A., Kubicki R., Wobec sztuki, [w:] tychże, Humanista w ponowoczesnym świecie, Wydawnictwo Zysk i S-ka, Poznań 1997.

Burrell G., Morgan G., Sociological Paradigms and Organizational Analysis, Heinemann, London 1979.

Cameron, J., The Artist's Way: A Spiritual Path to Higher Creativity, Pan Books, London 1995.

Czarniawska B., Zarzq̨dzanie humanistyczne czy zarzadzanie ludzkie?, [w:] B. Nierenberg, R. Batko, Ł. Sułkowski (red.), Zarządzanie humanistyczne, Wydawnictwo Uniwersytetu Jagiellońskiego, Kraków 2015.

Drozdowski R., Zakrzewska A., Puchalska K., Morchat M., Mroczkowska D., Wspieranie postaw proinnowacyjnych przez wzmacnianie kreatywności jednostki, Polska Agencja Rozwoju Przedsiębiorczości, Warszawa 2010.

Florida R., Narodziny klasy kreatywnej, Narodowe Centrum Kultury, Warszawa 2010.

Habermas J., Knowledge and Human Interests, Beacon Press, Boston 1972.

Hatch M.J., Teoria organizacji, Wydawnictwo Naukowe PWN, Warszawa 2002.

Hublin J.-J., New Fossils from Jebel Irhoud, Morocco and the Pan-African Origin of Homo Sapiens, „Nature” 2017, t. 546, s. 289-292.

Kanter R.M., eVolve!: Succeeding in the Digital Culture of Tomorrow, Harvard Business School Press, Boston 2001.

Keyes R., Czas postprawdy. Nieszczerość i oszustwa w codziennym życiu, Wydawnictwo Naukowe PWN, Warszawa 2017.

Klincewicz K., Koncepcja klasy kreatywnej Richarda Floridy i klasa kreatywna w Polsce, [w:] K. Klincewicz (red.), Klasa kreatywna w Polsce - technologia, talent i tolerancja jako źródła rozwoju regionalnego, Wydawnictwo Naukowe Wydziału Zarządzania Uniwersytetu Warszawskiego, Warszawa 2012.

Kopecka-Piech K., Spory o przemysty kreatywne, „Kultura i Edukacja” 2013, nr 3 (96), s. 50-72.

Lévi-Strauss C., Struktura mitu, [w:] K. Pomian, Antropologia strukturalna, Państwowy Instytut Wydawniczy, Warszawa 1970.

Mellor R.B., Kreatywność, [w:] R.B. Mellor, G. Coulton, A. Chick, A. Bifulco, N. Mellor, A. Fisher (red.), Przedsiębiorczość, PWE, Warszawa 2011.

Piotrowski W., Organizacja i zarzadzanie - kierunki, koncepcje, punkty widzenia, [w:] A. Koźmiński, W. Piotrowski, Zarządzanie - teoria i praktyka, Wydawnictwo Naukowe PWN, Warszawa 1996.

Sawyer R.K., Explaining Creativity - The Science of Human Innovation, Oxford University Press, Oxford 2006.

Schein E.H., Organizational Culture and Leadership, Jossey-Bass, San Francisco 1995.

Stachowiak K., Problemy metodologiczne badania sektora kreatywnego, [w:] P. Churski (red.), Rozwój regionalny i polityka regionalna, Bogucki Wydawnictwo Naukowe, Poznań 2015.

Stein M.I., Creativity and Culture, „Journal of Psychology” 1953, t. 36.

Sułkowski Ł., Czy warto zajmować się kulturą organizacyjną, „Zarządzanie Zasobami Ludzkimi" 2008, nr 6, s. 9-25.

Szomburg J., Kultura i przemysty kultury szansa rozwojowa dla Polski, [w:] J. Szomburg (red.), Kultura i przemysty kultury szansa rozwojowa dla Polski, Instytut Badań nad Gospodarką Rynkową, Gdańsk 2002.

Weick K., Tworzenie sensu w organizacjach, Wydawnictwo Uniwersytetu Jagiellońskiego, Kraków 2016.

Woodman R.W., Sawyer J.E., Griffin R.W., Toward a Theory of Organizational Creativity, „Academy of Management Review” 1993, nr 18 (2), s. 293-321. 
Zawadzki M., Rola i miejsce nurtu krytycznego w naukach o zarzadzaniu, „Culture Management" 2012, nr 5 (5).

Żelechowska D., Psychologia poznawcza na tropie kreatywności: twórca (zde)koncentrowany, [w:] A. Porowska, B. Mozyrko, P. Łupkowski (red.), Poznańskie Forum Kognitywistyczne. Teksty pokonferencyjne, Zakład Logiki i Kognitywistyki, Poznań 2009.

\section{Dokumenty elektroniczne}

UNCTAD, Creative Economy. Report [dok. elektr.], http://www.unctad.org/en/docs/ditc20082cer_en.pdf (dostęp: 18.12.2018). 